\title{
Um discurso sobre ruínas, origens e espaços eleitos
}

\author{
Afonso Henriques de Guimaraaens Neto \\ UFF
}

Em algum momento recuado da infância se imprime em nós uma como difusa percepção do espaço. Quando os olhos se abrem para o mundo; neste ponto dizer 'algum momento' não significa falar do tempo: abrir os olhos no mundo é, ali, viver espaço. Primeiros lugares, primeiros momentos; carinhoso, doce continuum espaço-temporal, caminho da pura emoção, coração celebrado.

Podemos dizer só do nosso; cada um irá dizer de si mesmo. Os fotogramas registrados na memória jogam com impressões caóticas: aqui as grades do berço; lá uma parede branca muito alta em canto quente, manchado de sol, do quarto; a seguir a superficie ladrilhada em vermelho e a recender perfume tão característico; então poeiras de luzes correndo com o vento e o automóvel sacolejando. Só mais tarde a idéia da casa plantada naquela rua defronte daquelas montanhas esverdeadas; depois a percepção de todas as ruas a se trançarem. formando o desenho chamado cidade. Esta idéia de espaços particulares a se somarem na busca da complexa trama urbana, estruturada por incontáveis e complexos movimentos. já representa talvez o fim da infância. Mas é de espaço que sempre estamos falando: o tempo é algo ainda muito lento, borrachentamente pegajoso, preguiçoso: o dia seguinte é algo que se arrasta dolorosa e demoradamente para fora do próprio tempo. Tudo espaço.

II

Perseguindo esta linha de pensamentos, mergulhamos em certas especialíssimas percepções de uma 'poética do espaço'. tão caras a 
Gaston Bachelard. Ao discorrer sobre um conceito a que nomeou de 'topoanálise', que em linhas gerais se' refere ao estudo psicológico sistemático dos lugares físicos de nossa vida mais íntima, diz o filósofo francês: "No teatro do passado que é a nossa memória, o cenário mantém os personagens em seu papel dominante. Às vezes acreditamos conhecernos no tempo, ao passo que se conhece apenas uma série de fixações nos espaços da estabilidade do ser, de um ser que não quer passar no tempo, que no próprio passado, quando vai em busca do tempo perdido, quer 'suspender' o vôo do tempo. Em seus mil alvéolos, o espaço retém o tempo comprimido. $\mathrm{O}$ espaço serve para isso." $\mathrm{E}$ mais adiante: "A memória - coisa estranha! - não registra a duração no sentido bergsoniano. Não se podem reviver as durações abolidas. Só se pode pensá-las na linha de um tempo abstrato privado de toda densidade. É pelo espaço, é no espaço que encontramos os belos fósseis de uma duração concretizados em longos estágios."

Sim. Cada um de nós cultiva mais ou menos secretamente seus luminosos fósseis particulares, esses comprimidos de tempos empedrados, transformados em faróis abertos sobre os territórios 'interiores' de nossa mais profunda eleição. Isto é por demais humano: seja do consciente ou mesmo do inconsciente fluem as raízes desses secretos aposentos, ocultos mas fosforescentes sinais que se convertem nos espaços idealizados do que de alguma forma foi nosso um dia e em nossa emoção permanece como destroço belo e terrível. Ao pensar a alma como 'guardiã' de toda a história humana, C. G. Jung também nos remete, de forma notável, ao que podemos chamar de espaços 'históricos' eleitos: "Temos que descobrir uma construção e explicá-la: seu andar superior foi construído no século XIX, o térreo data do século XVI e o exame mais minucioso da construção mostra que ela foi feita sobre uma torre do século II! No porão, descobriram fundações romanas e, debaixo do porão, acha-se uma caverna em cujo solo se descobrem ferramentas de sílex, na camada superior, e restos da fauna glaciária nas camadas mais profundas. Tal seria mais ou menos a estrutura de nossa alma."

Não temos receio em afirmar que pelo estudo de qualquer cidade não só nos será possivel compreender muito do povo, e correspondente cultura, que construiu aquele momento histórico particular, já que a cidade é uma estrutura especialmente edificada para conservar e transmitir os bens da civilização, como também navegar pelo interior do espírito humano tomado de forma genérica, no que ele tem de maior riqueza e for- 
ça criativas. Contudo, para um conhecimento cada vez mais percuciente e globalizante dessa especial estrutura chamada 'cidade', guardiã e retransmissora da herança cultural acumulada, não será necessário começarmos do princípio, da percepção e definição, tanta vez necessariamente poética, daqueles primeiros espaços que impressionaram para sempre a nossa alma amanhecente?

Como vimos na citação de Jung, todos os 'espacitempos', se 'hereticamente' assim pudermos dizer, convivem em nosso psiquismo de modo caótico e perturbador. Diriamos de uma operação em que certo 'naturalismo cientifico' se enlaçasse a uma percepção 'mágico-poética' dessas instâncias anímicas, fusão das forças emotivas com as do pensamento racionalista. Arqueologias do coração em estado 'selvagem' fundidas a métodos 'empíricos' que buscassem a abertura e a interpretação dos arquivos mais particulares, próximos assim da abordagem psicanalítica. Sem descurar, por óbvio, de uma 'leitura' estritamente científica dos fragmentos concretos de uma cidade desenterrada.

$\dot{E}$ desse território movediço, é dessa tentativa de se desenhar pela memória, pela sensibilidade e pela visada cientifica algumas linhas fortes sobre o universo opaco da amnésia que estamos falando. E se falamos de espaços eleitos de nossa infância. 'esvaziados' da duração temporal, estamos dizendo não só da cidade em que respiramos infância um dia, mas de todos os remotos passados que o conhecimento arqueológico segue desenterrando, para que ao menos se pense ser possivel remontar' a história de todas as sociedades humanas como se fosse algo semelhante a um gigantesco, e sempre incompleto ou até mesmo insolúvel, quebra-cabeça.

III

As origens da cidade como fato cultural que representou enorme salto qualitativo para a humanidade, remontam às aldeias primitivas construidas, entre outras localidades, na Mesopotâmia e no vale do Nilo entre 9 mil e 4 mil anos antes de nossa era. Lewis Mumford, em A cidade na história, nos diz que esta aldeia era "um aglomerado de cabanas de barro cozido ou de construções de caniço e lama, de tamanho atarracado, a princípio pouco melhores que a morada de um castor. Ao redor dessas aldeias, estendem-se canteiros e plantações. modestos em todas as dimensões: não ainda os campos largos mas delimitados, de forma retangular, que surgiram com o arado. Perto. no alagadiço e no rio. há 
aves a atrair e apanhar, peixes a pegar na rede, alimentos a mais para compensar más colheitas ou enriquecer a dieta de cada dia." E prossegue: "Note-se o quanto a cidade deve, tecnicamente, à aldeia: dela surgiram, diretamente ou pela elaboração, o celeiro, o banco, o arsenal, a biblioteca, o armazém. Lembremo-nos também de que a vala de irrigação, o canal, o reservatório, o fosso, o aqueduto, o dreno, o esgoto, também constituem recipientes destinados ao transporte automático ou à armazenagem. $\mathrm{O}$ primeiro deles foi inventado muito antes da cidade; e sem essa ordem de invenções, a cidade antiga não poderia ter tomado forma, como afinal ocorreu."

Antes dessas remotas aldeias podemos imaginar o acampamento, 0 esconderijo, a caverna, o monte de pedras. E sob a predisposição à vida em sociedade, comum aliás a quase todas as espécies animais, também imaginamos as andanças sem destino dos grupos de homens paleolíticos, deixando marcados nas cavernas ou através de pedras empilhadas ao longo dos caminhos, os túmulos individuais e coletivos. Esta sinalização significava a possibilidade de se retornar àqueles locais para uma verdadeira comunhão com os espíritos dos ancestrais. Assim, foram surgindo, principalmente nas cavernas, os espaços cerimoniais, os primeiros santuários paleolíticos onde se encontram também os primitivos indícios de vida cívica. Mumford assinala: "Ali no centro cerimonial verificava-se uma associação dedicada a uma vida mais abundante; não simplesmente um aumento de alimentos, mas um aumento do prazer social, graças a uma utilização mais completa da fantasia simbolizada e da arte, com uma visão comum de uma vida melhor e mais significativa, ao mesmo tempo que esteticamente atraente, uma boa vida em embrião, como o que Aristóteles um dia iria descrever na Política: o primeiro vislumbre de Eutópia."

A partir daí há que se falar do advento da 'revolução agrícola', com o papel masculino de ágil e forte caçador se transformando em guardião da mulher, dos filhos e das mudas de plantas. Este assentamento do homem à terra, que conduziu à ampliação dos suprimentos alimentares, desencadeou a formação das aldeias primitivas. A presença feminina é então mostrada de uma forma altamente positiva por Lewis Mumford: "Era a mulher que manejava o bastão de cavar ou a enxada: era ela que cuidava dos jardins e foi ela quem conseguiu essas obras-primas de seleção e cruzamento que transformavam espécies selvagens e rudes em variedades domésticas prolíficas e ricamente nutritivas; foi a mulher 
que fabricou os primeiros recipientes, tecendo cestas e dando forma aos primeiros vasos de barro. Na forma, também, a aldeia é criação sua: não importa que outras funções pudesse ter, era a aldeia o ninho coletivo para o cuidado e nutrição do filho. (.....) A presença da mulher se fez sentir em todas as partes da aldeia: não menos em suas estruturas fisicas, com seus lugares fechados para proteção, cujos sentidos simbólicos posteriores a psicanálise trouxe, agora tardiamente, à luz. Segurança, receptividade, proteção e nutrição - tais funções pertencem à mulher: e tomam expressão estrutural em todas as partes da aldeia, na casa e no forno, no estábulo e no celeiro, no poço, no paiol, no silo, e dali passam à cidade, refletindo-se na muralha e no fosso e em todos os espaços internos, desde o átrio até o claustro. A casa e a aldeia, e com o tempo a própria cidade, são obra da mulher. (......) Nos hieróglifos egípcios, 'casa' ou 'cidade' podem surgir como simbolos de 'mãe', como a confirmar a semelhança da formação individual e coletiva. Ao lado disso, as estruturas mais primitivas - casas, aposentos, túmulos -, geralmente são redondas, lembrando o vaso original descrito no mito grego, que fora modelado no seio de Afrodite."

Dessa cultura neolítica, em união com uma cultura paleolitica mais arcaica, surgem as protocidades, ambiências proto-urbanas onde a muIher alcança proeminencia, conforme vimos, para aos poucos tornar a ceder espaço à força masculina. Na realidade, as artes da guerra e da conquista começam logo a se sobrepor àquelas artes eminentemente femininas, tal o desenho dos objetos de uso cotidiano e das próprias construções do espaço proto-urbanos. Assentados na terra, resolvido o problema imediato da nutrição dos filhos, os homens passam de novo a olhar para além dos limites de sua casa, de sua terra, de sua aldeia. Troca-se, assim, a proteção e a prudência pela luta, pela necessidade de domínio do outro. E nas aldeias primitivas, conforme mostram as escavações, já proliferam agora os símbolos masculinos: a linha reta, o retângulo, a torre, o obelisco.

\section{IV}

Os mitos fundadores das cidades estão mergulhados em noite pontithada de conjecturas. Há alguns fatores já conhecidos no que se refere à origem da cidade, onde ressalta a emergência dessa comunidade paleoneolítica de que acabamos de falar. Os antigos componentes da aldeia, graças à ação de novos fatos, foram recompostos em um padrão mais 
complexo. Isto se deu, essencialmente, pela nova composição dos grupos humanos, estabelecidos em acordo com suas renovadas necessidades e atividades. É ainda Lewis Mumford quem ensina: "Além do caçador, do camponês e do pastor, outros tipos primitivos introduziram-se na cidade e emprestaram contribuição à sua existência: o mineiro, o lenhador, o pescador, cada qual levando consigo os instrumentos, habilidades e hábitos de vida formados sob outras pressões. $O$ engenheiro, o barqueiro, o marinheiro, surgem a partir desse fundo primitivo mais generalizado, em um ou outro ponto da secção do vale: de todos esses tipos originais, desenvolvem-se ainda outros grupos ocupacionais, o soldado, o banqueiro, o mercador, o sacerdote. Partindo dessa complexidade, criou a cidade uma unidade superior."

Não é meu interesse discutir exaustivamente sobre as origens da cidade. $\mathrm{O}$ que me importa é levantar alguns pontos que sempre despertaram minha curiosidade e que, paralelamente, facilitem a continuidade dessas reflexões. Falava em conjecturas: na realidade, as lacunas existentes na tentativa dos arqueólogos de escrever uma história das origens da cidade são inumeráveis. Os 5 mil anos de história urbana, e outros tantos relativos ao período proto-urbano, são estudados através de poucos monumentos e algumas centenas de documentos escritos. Nenhuma cidade arcaica foi até hoje completamente desenterrada, e algumas das mais antigas continuam totalmente escondidas, senão definitivamente perdidas. Os grandes sítios urbanos, sobre os quais os especialistas se debruçam em busca de informações científicas, como os de Ur, Nipur, Uruk, Tebas, Heliópolis, Assur, Nínive ou Babilônia, não solucionam as imensas dificuldades. O terreno permanece coberto por neblinas, vácuos, muito silêncio. Os mitos fundadores, os marcos da memória, a história factível, sejo o que for, se oculta, se esquiva, e mais uma vez nos vemos encharcados pelo mar das suposições. $\mathrm{E}$ a luta prossegue, e novas escavações, com tecnologia cada vez mais avançada, conduzem a leituras renovadas. Há sempre a esperança, afinal, de que se possa um dia narrar, sem lacunas, toda a peregrinação humana por importantes cidades que se construíram e se destruíram, às vezes repetindo esta diástole várias vezes, ao longo de poucos milênios.

O exame das ruínas até hoje desenterradas conduz, ao lado dos indícios que buscam esclarecer o conteúdo das instituições e da vida social, a duas características presentes na passagem da aldeia para a cidade: 
primeiro, é o evidente aumento da área construida, com o conseqüente crescimento populacional. Contudo, em média a dimensão de uma cidade antiga era próxima ao que hoje chamaríamos um pequeno bairro residencial, com cerca de 5 mil habitantes. Obviamente há exceções, como no caso da velha Ur, florescida por volta de 2.000 a.C., e que contava com 50 casas por hectare, o que lhe dava uma densidade de até 500 pessoas por hectare, superior à que era higienicamente desejável. Esta cidade deveria ter cerca de $30 \mathrm{mil}$ habitantes. Mais tarde ela iria se transformar em importante centro manufatureiro e atingiria cerca de 200 mil moradores.

A outra característica sempre encontrada nas cidades antigas se refere à construção de muralhas protetoras, sempre rodeadas por uma ou mais povoações exteriores, à semelhança de satélites orbitando o astro central. Além do oferecimento de proteção contra o ataque de inimigos, as muralhas impunham claros limites ao tamanho das cidades. Este fato, enfim, era essencial seja para o controle da disponibilidade da água e dos alimentos, seja para o controle politico-institucional exercido pelo castelo e pelo templo. Lewis Mumford acrescenta: "As cidades mesopotâmicas tinham um tambor de reunir, assim como as cidades medievais utilizavam o sino de uma torre de igreja para ajuntar seus cidadãos. As cidades antigas não cresceram além das distâncias de caminhada ou de audição. $\mathrm{Na}$ Idade Média, ficar dentro do alcance dos sinos de Bow definia os limites da City de Londres."

$\mathrm{Na}$ Idade Moderna irão se operar as vertiginosas fraturas desses limites, até o advento do que hoje se diz Megalópole, ou Caóspole, ou quem sabe a imensa, labirintica e provavelmente apocaliptica Necrópole. Basta pensar nas gigantescas cidades como verdadeiras câmaras de gases de toda ordem a influirem não só na saúde da população, mas no efeito estufa a contaminar progressivamente todo o planeta de forma ainda para nós inimaginável. Ou pensar também na poluição e no esgotamento dos recursos naturais, principalmente a água, com toda a cadeia de desastres já de certa forma previstos nos manuais técnicos sobre o futuro dessas conurbações. desses cânceres que um dia se chamaram aldeia ou cidade.

Se sempre me comoveu o trabaho do arqueólogo. ou do 
paleontólogo, cientistas que pacientemente recolhem os fragmentos de um passado que, no caso das cidades arcaicas, quase nunca deixou rastro documental, para entre cacos e vagas partículas, ir reescrevendo na bruma, ou desentranhando do vento, a história de uma aldeia, de um povo, de uma cidade, assim como de uma espécie animal ou vegetal; se sempre me comoveu este paciente labor, esta aguda música entre ruínas, esta estranha necessidade de se 'congelar', 'cristalizar' o efêmero, como se assim pudéssemos estar imunes à própria morte, posso falar da emoção que me envolveu quando visitei a única cidade do mundo antigo preservada intacta pelas cinzas de um vulcão: Pompéia.

Visitar suas ruínas é emoção difícil de narrar. Posso dizer de uma fantasia infantil, exemplo de pura onipotência, quando desejava que 0 oceano recuasse até o horizonte para que me fosse mostrado todo o mistério a respirar sob as águas: sensação semelhante me invadiu quando principiei a caminhar por Pompéia em uma tarde ensolarada de meio de semana, ou seja, quando raros eram os visitantes. Em vez das águas da fantasia infantil, toda a terra havia sido realmente retirada de sobre a cidade. O silêncio impressionante a emanar das construções agora sem préstimo me envolveu, estranha cápsula, estranho espaço recém-arrancado de seu túmulo e como que lançado em nova vida, quase diria vegetativa, imune ao tempo. Tudo se paralisara repentinamente sob uma tempestade de cinzas quentes expelidas com violência pela chaminé incandescente do Vesúvio, a erguer-se soberbo quilômetros adiante, naquele recuado ano de 79 d.C.. Como se pode ver no museu à entrada da cidade, muitos dos corpos humanos encontrados nas escavações narravam em seus pânicos gestos petrificados todo o horror da súbita tragédia. Só a partir do século XVIII Pompéia começou a ser desenterrada, revelando-se assim, pouco a pouco, todas as características da vida de uma próspera e bela cidade, de cerca de 30 mil habitantes, onde o comércio se desenvolvia com vigor.

A cidade permaneceu preservada por quase 2 mil anos. No calçamento pétreo das ruas estão as marcas das rodas das bigas e carroças. Nas alamedas para pedestres, obstáculos de pedra se erguem no meio do caminho. Na soleira de uma residência vê-se o mosaico representando um cão e o aviso do perigo; em muitas paredes se encontram propagandas eleitorais, mensagens entre namorados, citações de Virgílio e Propércio. De repente a casa do fauno dançando, belíssima escultura colocada no centro do jardim de uma rica residência, com paredes inte- 
riores contendo pinturas lindíssimas. Adiante, um teatro e um prostíbulo, com suas camas de pedra em cada cubículo, onde se vê sobre os portais decorações ilustrando as posições sexuais clássicas. $E$ mais uma padaria, e uma quitanda, e residências atrás de residências, e então a bela praça do fórum, com seu grupo de prédios públicos dispostos com elegância e equilíbrio.

Esta talvez seja a melhor palavra para definir o desenho urbano e as construções de Pompéia: equilíbrio. As praças da cidade são muito bem planejadas. Os ginásios, as arenas, os anfiteatros, tudo é de uma singeleza, de uma beleza tão apolínea e emocionante, que me sento sobre uma antiga pedra, onde incontáveis habitantes um dia já se sentaram, e espero que o sol vá lentamente coando sua luminosidade por entre as ramagens das árvores e riscando em luz e sombra as paredes em torno da ampla praça, mas não tão ampla que nossa voz não possa alcançar o lado oposto. Equilíbrio: tudo edificado na escala do homem. Nada tão majestoso que o esmague, nem tão canhestro que o amesquinhe. Equilíbrio greco-romano, alto exemplo de beleza nesta mágica cidade entardecendo.

Se o trabalho do arqueólogo sempre despertou também a minha curiosidade, posso falar das muitas surpresas, geradas pelos resultados dessas escavações em busca do tempo perdido, que se gravaram de algum modo em mim. Se Pompéia é o único caso de uma cidade antiga desenterrada praticamente intacta, todas as demais nos chegam em fragmentos, em cacos, em conjecturas, em teias labirínticas para o entendimento ou para a tentativa de se reescrever memórias em meio a tantas lâminas de esquecimento.

Fatos interessantíssimos nos chegam, por exemplo, da arqueologia realizada atualmente na Palestina. Vamos nos ater à pesquisa do primeiro século de nossa era em cidades bíblicas, caras à nossa tradição judaico-cristã, e tomarmos dois exemplos bem marcantes. Em Cafarnaum as escavações recentes descobriram, com enorme possibilidade de acerto, a própria casa de S. Pedro, onde Cristo possivelmente instruiu e praticou milagres. No livro Jesus dentro do judaismo, de James $\mathrm{H}$.. Charlesworth, encontramos o trecho que nos esclarece sobre essa busca de se 'ler' o passado de um determinado espaço urbano, a partir das evidências que se vão descobrindo nas relações entre fatos históricos preservados e o que na realidade se vai desenterrando do solo em exame, à maneira daquelas 'camadas' históricas que narram a vida de uma velha 
construção e que Jung aproximou da própria 'estrutura' da alma humana. Dir-se-ia tratar, em última análise, de uma explicitação do modus operandi da ciência arqueológica, e por isso transcrita na totalidade: "Sete estágios das pesquisas levam à conclusão de que a casa de Pedro possa ter sido descoberta. Primeiro, os peregrinos antigos, como Egeria, que visitou Cafarnaum entre 381 e 384 d.C., identificam o lugar como sítio da casa de Pedro e dos primeiros cultos cristãos. Em segundo lugar, a casa contém cruzes gravadas, um barco e mais de uma centena de grafitos gregos, aramaicos, siríacos, latinos e hebreus de cristãos dos séculos segundo e terceiro que veneraram o lugar. Terceiro, a casa está situada sob uma igreja octogonal do século V, um tipo de arquitetura especialmente usado para venerar lugares sagrados mais antigos (uma igreja octogonal foi construída por ordem de Constantino sobre o sitio celebrado como sendo o local de nascimento de Jesus, em Belém). Em quarto lugar, a casa foi provavelmente construída entre 100 e 60 a.C., em razão das condições estratigráficas e da recuperação de antigas candeias e moedas herodianas. Em quinto lugar, foram achados anzóis debaixo do pavimento do que é identificado como sendo uma casa-igreja; por isso é concebível que ali tenha vivido um pescador. Em sexto lugar, é evidente um pavimento antigo, notadamente o Pavimento Romano $\mathrm{B}$, mas o mais notável é a descoberta de que o chão e as paredes da casa foram argamassados não menos do que três vezes, a partir de meados do primeiro século d.C.. O grande aposento foi aparentemente modificado para algum uso público por volta da metade do primeiro século d.C.. Em sétimo lugar, o grande aposento, depois de argamassado, foi provavelmente convertido numa 'casa-igreja' (em Cafarnaum não foram encontradas outras casas com argamassa). Nesse aposento amplo só foram desenterrados grandes jarros para armazenamento e candeias a óleo: não se recuperou qualquer cerâmica de uso doméstico."

Por fim, são muito curiosas as relações construídas entre trechos do Novo Testamento e das escavações que têm revelado as verdadeiras feições, no primeiro século cristão, do Templo de Jerusalém, onde vários episódios da vida de Jesus se desenrolaram. A arqueologia desse sítio tem demonstrado fatos interessantes. Josefo, o importante historiador do primeiro século da Palestina, falara do incrivel tamanho das pedras utilizadas na construção do Templo de Jerusalém, mas os eruditos posteriores quase sempre rejeitaram essas cifras por exageradas. Contudo, escavações recentes revelaram que o Templo construido por Herodes, o 
Grande, era na realidade uma das maravilhas do mundo antigo. Para se ter uma idéia da ordem de grandeza dessa construção, a maior pedra utilizada na edificação das Pirâmides atinge cerca de 15 toneladas, e a mais pesada de todas as pedras até então desenterrada de construções antigas era a de Stonehenge, com 40 toneladas. Contudo, acaba de ser encontrada uma pedra do Templo de Herodes pesando cerca de 450 toneladas. A grandiosidade do Templo vai, assim, além do que o próprio Josefo deixou registrado, e ganham foros de impressionante realismo as palavras de um dos discípulos de Cristo ao entrar naquele espaço, segundo se lê em Marcos (13:1): "Mestre, olha que pedras, que construções magníficas!"

Outra descoberta arqueológica bastante curiosa se relaciona diretamente com o episódio da indignação de Jesus no Templo. Dos Evangethos canônicos, o de João é o único que fala haver Jesus expulsado os comerciantes do Templo, juntamente com bois e ovelhas, tendo utilizado de um chicote com cordas feito por ele na ocasião. Até as recentes descobertas, esse trecho era interpretado como sendo apenas obra teológica sem valor histórico, escrita por alguém que desconhecia Jerusalém. Afinal, por que falar em ovelhas e, principalmente, bois dentro do Templo? Em nenhum outro texto da época havia qualquer referência a tal fato. Contudo, como nos diz Charlesworth, "foram agora descobertas as duplas e triplas Portas de Hulda, na muralha meridional do Templo, e também partes da maciça escada de pedra anterior a $70 \mathrm{~d}$.C., de praças e caminhos. Os mercadores podiam ficar dentro dessas portas maciças; e uma passagem dessa área, através das Portas Duplas, para os chamados Estábulos Salomônicos foi agora, ao que tudo indica, descoberta. De inicio, sabíamos que estes últimos continham no tempo de Herodes cocheiras para grandes animais, mas não se podia encontrar qualquer ligação com o Templo. Agora. fica claro que grandes animais podiam ter sido conduzidos dessas cocheiras (que ainda revelam nichos onde grandes animais eram presos) para as salas dos cambistas. E das camas ou cordas de palha que acompanhavam tais animais Jesus poderia ter facilmente fabricado um chicote."

A realidade e a paródia da realidade; o dado cientifico e os ventos da conjectura. Não há descrição possível de qualquer espaço eleito sem forte carga emotiva correspondente. Desenterrar espaços mortos será como reencenar emoções cristalizadas por séculos de terra e esquecimento. Redescobri-las, intactas. Reescrever pela sensibilidade todo um 
desenho urbano recém-outra vez-nascido das toneladas de tempo, pedra e amnésia. Re-presentar em música, pintura, reflexão ou poesia, se tudo não forma única ambiência polissêmica, os caminhos dos espaços eleitos, violentos ou pacíficos, complexos ou singelos, estradas de tanta emoção, coração celebrado.

\section{Referências Bibliográficas}

BACHELARD, Gaston. "A poética do espaço", volume XXXVIII, Coleção "Os Pensadores”, São Paulo: Ed. Abril, 1974.

CHARLESWORTH, James H. Jesus dentro do judaismo, Rio de Janeiro: Ed. Imago, 1996.

MUMFORD, Lewis. A cidade na história, Belo Horizonte: Ed. Itatiaia, 1965. 